\title{
Avaliação dos fatores intervenientes no processo de salinização em reservatórios superficiais do semiárido brasileiro
}

\section{Assessment of factors involved in the process of salinization in surface reservoirs of the Brazilian semiarid}

\author{
Andrea Sousa Fontes ${ }^{1}$; Maria do Rosário Zucchi ${ }^{2}$; Yvonilde Dantas Pinto Medeiros ${ }^{3}$ \\ e Antonio Expedito Gomes de Azevedo ${ }^{4}$ \\ andreafontes@ufrb.edu.br; maria.zucchi@gmail.com; yvonild@ufba.br; expedito@ufba.br
}

${ }^{1}$ Universidade Federal do Recôncavo da Bahia, Feira Santana, BA. Brasil

${ }^{2,3,4}$ Universidade Federal da Bahia, Salvador, BA. Brasil

Recebido: 14/05/14 - Revisado: 09/08/14 - Aceito: 18/03/15

\begin{abstract}
RESUMO
Os açudes representam a principal fonte de água para suprir as demandas no semiárido do nordeste brasileiro. A presença da água não significa garantia de abastecimento, uma vez que, além da intermitência dos rios, o aporte de sais e esgotos na água torna-a comprometida para o consumo humano, animal e para a irrigação. Neste contexto, a presente pesquisa avaliou o processo de salinização das águas superficiais de cinco reservatórios com características distintas da bacia bidrográfica do rio Jacuípe, uma área de $12.163 \mathrm{~km}^{2}$ representativa da região semiárida, por meio da utilização de traçadores ambientais (isotópicos e químicos). De acordo com os resultados encontrados, foram estabelecidas relações entre fatores climáticos (ocorrência de precipitação e ação da evaporação), características químicas da água armazenada e o comportamento hídrico dos reservatórios. As relações identificadas contribuem para o entendimento do processo de salinização de reservatórios dessa região. Nas análises foram consideradas também informações da área de drenagem no que se refere ao aporte de sais proveniente da lavagem deste pela chuva, características geométricas do lago, seu tamanho e existência de barramentos a montante. As análises indicaram que a salinização é proveniente da dissolução de sais, presente no solo, e a evaporação é o agente intensificador. A entrada de água de afluentes com água salobra, trazendo os sais carreados do solo, colabora com o aumento da salinidade. O estudo do tipo e controle do uso do solo na área de drenagem deve ser priorizado de modo a orientar na construção e gestão de reservatórios de águas da região semiárida na tentativa de minimizar os impactos da salinização na qualidade desse recurso.
\end{abstract}

Palavras Chave: salinização. Semiárido. Traçadores ambientais

\begin{abstract}
The dams are the main source of water to meet the water demands in the semiarid region of northeastern Brazil. The presence of water does not mean supply guarantee, since, in addition to the flashing of rivers, salts and the supply of sewage, water becomes compromised for human and animal consumptions, and for irrigation. In this context, the present paper evaluated the salinization process of surface water from five reservoirs with distinct features on the Jacuipe river basin, an area of 12,163 $\mathrm{km}^{2}$ representative of the semiarid region, through the use of environmental tracers (isotopic and chemical). According to the results, relationships among climatic factors (precipitation events and evaporationaction), chemical characteristics of the water stored and water behavior of the reservoirswere established. The relationships identified contribute to the understanding of the reservoir salinization process that region. In the analyzes were also considered information of the drainage area regarding the contribution of salts coming from washing out by rain, lake geometric characteristics, its size and the existence of dam upstream. The analyses indicated that the salinity is from dissolving salts present in the soil, and evaporation is the enhancing agent. Water entering of the branches with brackish water, bringing the salts from the soil washed down, collaborates with salinity increase. The study of the soil type and land use in the catchment should be prioritized in order to guide the construction and management of reservoir on the semiarid region in an attempt to minimize the impacts of the salinization on the water quality.
\end{abstract}

Keywords: Salinization. Semiarid. Environmental tracers 


\section{INTRODUÇÃO}

O semiárido do nordeste brasileiro é caracterizado por uma grande variação temporal e espacial da precipitação, ocorrendo a estação chuvosa em um único período, de 3 a 5 meses ao ano, e por pouca ou nenhuma vazão de escoamento nos rios durante a maior parte do ano. $\mathrm{O}$ atendimento à demanda da população nessa região é um desafio constante, na busca de atingir um nível satisfatório de convivência com essas características climáticas. Assim, a construção de barragens em rios configura uma alternativa recorrente para reservar água, e promover condições adequadas de vida e de desenvolvimento no semiárido.

Vorosmarty e Meybeck (2004) sugerem que os impactos de armazenamentos, desvios e redirecionamento de escoamento para atendimento às demandas de água, podem superar os impactos das recentes e antecipadas mudanças climáticas no escoamento superficial. Consequências desses efeitos incluem mudanças na frequência e extensão de escoamento, na produção e transporte de sedimentos, alteração na recarga de aquíferos e degradação da qualidade da água em ecossistemas hídricos, o que geralmente resultam conflitos entre usuários (montante jusante) ou em disputas políticas.

A salinidade do rio normalmente cresce ao longo do seu curso, sendo a sua origem geralmente de difícil determinação. As fontes potenciais de salinização das águas superficiais de uma bacia hidrográfica incluem: (i) deposição atmosférica de aerossóis marinhos, (ii) sais provenientes da dissolução do solo e rochas que fornecem sais aos aquíferos que ao atingir as águas superficiais intensificam a salinidade do manancial, e (iii) fontes antropogênicas. O solo é um componente fundamental no processo de salinização das águas superficiais, como fornecedor primário dos sais ou como depositário destes. Segundo Teixeira et al. (2008), as características da variabilidade climática, com chuvas concentradas e de forte intensidade e altas taxas de evaporação, são responsáveis pela dinâmica de aporte e concentração de sais nos mananciais. A evaporação na bacia assume papel importante no processo de salinização quando supera a precipitação, característica comum de regiões áridas e semiáridas. Ela promove a inversão sazonal da infiltração, quando uma parte da água subterrânea tem movimento ascendente por capilaridade no solo. Este processo é responsável pela mineralização dos horizontes superficiais do solo, pois sais dissolvidos nas águas subterrâneas acabam precipitando e cimentando grãos que salinizam os solos.

Para Molle (1994) dentre os fatores que influenciam no processo de salinização das águas represadas estão: (i) a natureza da bacia de drenagem, considerando o seu relevo e, sobretudo, as características do solo e subsolo; (ii) o tamanho do reservatório que interfere na possibilidade de vertimentos regulares do mesmo; (iii) a profundidade do açude, por determinar a lâmina evaporada com relação ao volume armazenado; e (iv) a operação do reservatório, pois, ao se retirar água para uso, também se retira os sais nele contidos. Em resumo, as características fisioclimáticas da bacia de contribuição do reservatório, seu dimensionamento e parâmetros geométricos, bem como sua operação são cruciais para entender e amenizar o processo de salinização que ocorrem nas águas armazenadas superficialmente no nordeste brasileiro. O adequado entendimento das fontes de salinização e dos processos que afetam seu aumento é necessário para a avaliação da vulnerabilidade hídrica a salinização de uma bacia hidrográfica e suas reservas de água, orientando ações para a gestão eficiente e sustentável dos recursos hídricos. Para tanto são necessárias: a caracterização dos fluxos de água na bacia e a definição da dinâmica das trocas de sais entre os corpos d'água, o solo e a atmosfera.

Segundo Vitvar e Aggarwal (2007) a água que escoa nos rios carrega uma memória integrada dos processos hidrológicos na bacia. Da mesma forma que águas armazenadas nos reservatórios, sujeitas aos processos do ciclo hidrológico, guardam características desses processos na sua composição molecular.

Assim, as características dos isótopos do hidrogênio e oxigênio que compõem a molécula da água podem ser utilizadas como traçadores dos caminhos que essa água percorreu e dos processos do ciclo hidrológico que interferiram no manancial.

Desde 1960, os isótopos têm sido usados para traçar caminhos de poluentes e de perdas de água devido a evaporação em rios. Kendall e Coplen (2001) realça a correlação entre águas da chuva e do rio, sugerindo que em grandes escalas, assinaturas isotópicas de rios geralmente preservam a composição isotópica das precipitações.

Rozanski et al. (2001) indicam o uso dos isótopos do oxigênio e hidrogênio para estudos em lagos para quantificação do balanço hídrico e identificação da interação com a água subterrânea adjacentes. Como uma grande parte da chuva retorna para atmosfera pela evaporação, a assinatura isotópica residual na vazão quando monitorada regularmente contém informações sobre o caminho terrestre da água (ciclo hidrológico) e o tempo de trânsito. Nos estudos hidrológicos se utiliza os isótopos como ferramenta para obter informações sobre origem,evaporação, idade, infiltração e fluxo da água, uma vez que diferentes isótopos de um mesmo elemento apresentam comportamentos distintos. Estas diferenças vão produzir uma separação parcial, entre os isótopos leves e pesados, chamada de fracionamento isotópico.

Dessa forma o grau de enriquecimento isotópico fornece informação sobre a quantidade de água perdida por evaporação direta da água superficial. Segundo Ladoucheet al. (2001), para obter as origens espacial e temporal do escoamento devem ser feitas investigações isotópicas e geoquímicas. O uso de traçadores isotópicos associado a dados geoquímicos permite identificar a influência dos processos do ciclo da água na origem dos componentes do escoamento.

Segundo Phillips et al. (2001), com a relação direta dos valores isotópicos de uma água com a evaporação, e desta com a salinização em açudes, assim como, pela possibilidade de identificação dos caminhos percorridose contribuições subterrâneas, esses traçadores ambientais podem ser utilizados para identificar e separar as diferentes fontes de salinidade, assim como o efeito da evapotranspiração nesse processo nas águas das regiões semiáridas. Os principais traçadores empregados têm sido os isótopos estáveis do oxigênio e do hidrogênio da molécula da água e os íons maiores, dentre os quais destaca-se o cloro. O cloro é utilizado como traçador em água em condições naturais, uma vez que é altamente conservativo e solúvel. 
Simpson e Herczeg (1991) apresentam medidas mensais da composição dos isótopos estáveis da água e concentração de cloro em 26 estações ao longo do rio Murray, na Austrália, clima semiárido, e nos seus maiores tributários de dezembro de 1988 a junho de 1989. Pelas análises feitas, grandes mudanças no deutério refletem evaporação acumulativa, enquanto que grandes mudanças no cloreto sem aumento concomitante do deutério refletem entrada de água subterrânea.

O uso de isótopos estáveis do hidrogênio e oxigênio como traçadores em estudos hidrológicos vem expandindo-se ao longo das últimas cinco décadas, com aplicação e validação em estudos de evaporação em reservatórios (DINCER, 1968; GAT, 1970; DANSGAARD, 1964; GAT, 1996; MACHAVARAN M.; KRISHNAMURTHY. 1994; GIBSON et al., 1996; GIBSON, 2002a); estudos do comportamento do escoamento superficial (HITCHON; KROUSE 1972); (MOORE, 1989; CAMERON et al., 1995; GIBSON et al., 2002b).

O presente artigo tem como objetivo avaliar a interferência das características físicas (evaporação, precipitação, características da área de drenagem) e morfológicas (tamanho e geometria) locais no processo de salinização dos reservatórios do semiárido, utilizando cinco reservatórios localizados em uma bacia representativa desta região no nordeste brasileiro, a Bacia do Rio Jacuípe.

\section{MATERIAIS E MÉTODOS}

\section{Área de Estudo}

O estudo foi realizado em cinco reservatórios situados na bacia hidrográfica do rio Jacuípe, com área de drenagem de $12.163 \mathrm{~km}^{2}$, sendo dois (França e São José do Jacuípe) no curso principal e os outros (São Domingos, Nenenzinho e Flori) localizados na Bacia Experimental do rio do Cedro, pequeno afluente do rio Jacuípe, com área de drenagem de $20 \mathrm{~km}^{2}$, monitorada pela Universidade Federal da Bahia - UFBA.

Essa bacia está localizada na região semiárida, na parte central norte da bacia do rio Paraguaçu (Figura 1) e o rio principal: (i) contribui diretamente para o reservatório da barragem Pedra do Cavalo do rio Paraguaçu, que abastece a capital do Estado, (ii) é responsável pelo abastecimento humano e diluição de efluentes de esgotos domésticos dos municípios da região, e (iii) apresenta comprometimento das vazões regularizadas no atendimento às demandas, devido às características climáticas da região e aspectos de qualidade da água.

O Quadro 1 apresenta as principais características dos reservatórios analisados e as Figuras 2 e 3 suas localizações.

Quadro 1 - Características dos reservatórios estudados na Bacia do rio Jacuípe

\begin{tabular}{|c|c|c|c|c|c|c|}
\hline Barragem & Município & Rio & $\begin{array}{c}\text { Área de } \\
\text { drenagem }\left(\mathbf{k m}^{2}\right)\end{array}$ & $\begin{array}{c}\text { Altura } \\
\text { máxima (m) }\end{array}$ & Volume $\left.\mathbf{( h m}^{3}\right)$ & $\begin{array}{c}\text { Área } \\
\text { alagada }\left(\mathbf{k m}^{\mathbf{2}}\right)\end{array}$ \\
\hline $\begin{array}{c}\text { França } \\
\text { ã̃o José do } \\
\text { Jacuípe }\end{array}$ & Piritiba & Jacuípe & $1.895,00$ & 25,5 & 24,2 & 4,974 \\
\hline $\begin{array}{c}\text { São } \\
\text { Domingos } \\
\text { Jacuípe }\end{array}$ & São Domingos & Cedro & $4.922,98$ & 41,0 & 355,0 & 39,100 \\
\hline Nenenzinho & São Domingos & Cedro & 20,53 & 15,0 & 1,966 & 1,041 \\
\hline Flori & São Domingos & Cedro & 11,14 & 3,0 & 0,174 & 0,162 \\
\hline
\end{tabular}

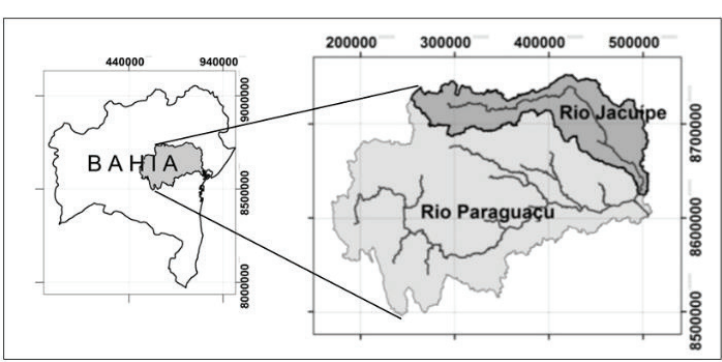

Figura 1 - Localização da bacia do rio Jacuípe. Fonte: Fontes (2011)

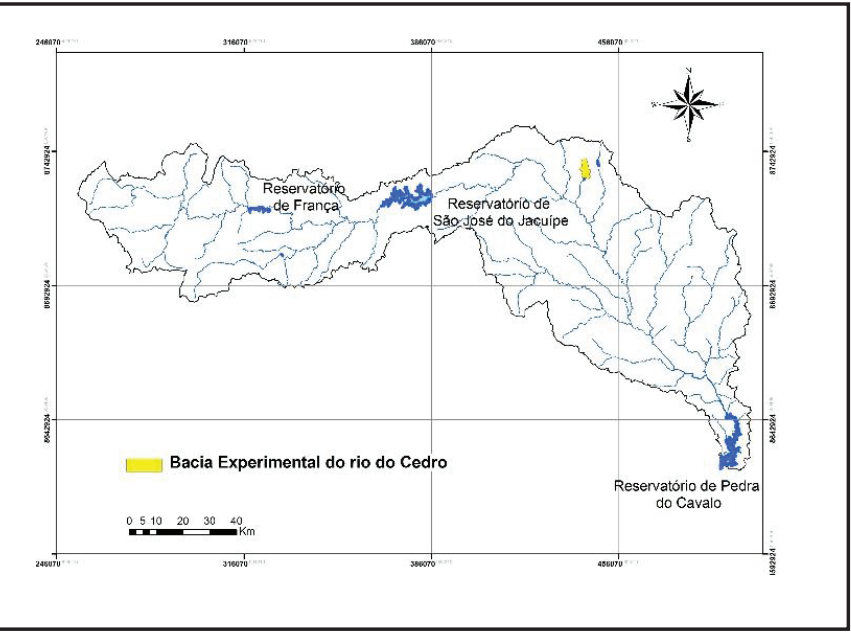

Figura 2 - Localização da bacia experimental do rio do Cedroe dos reservatórios na bacia do rio Jacuípe 


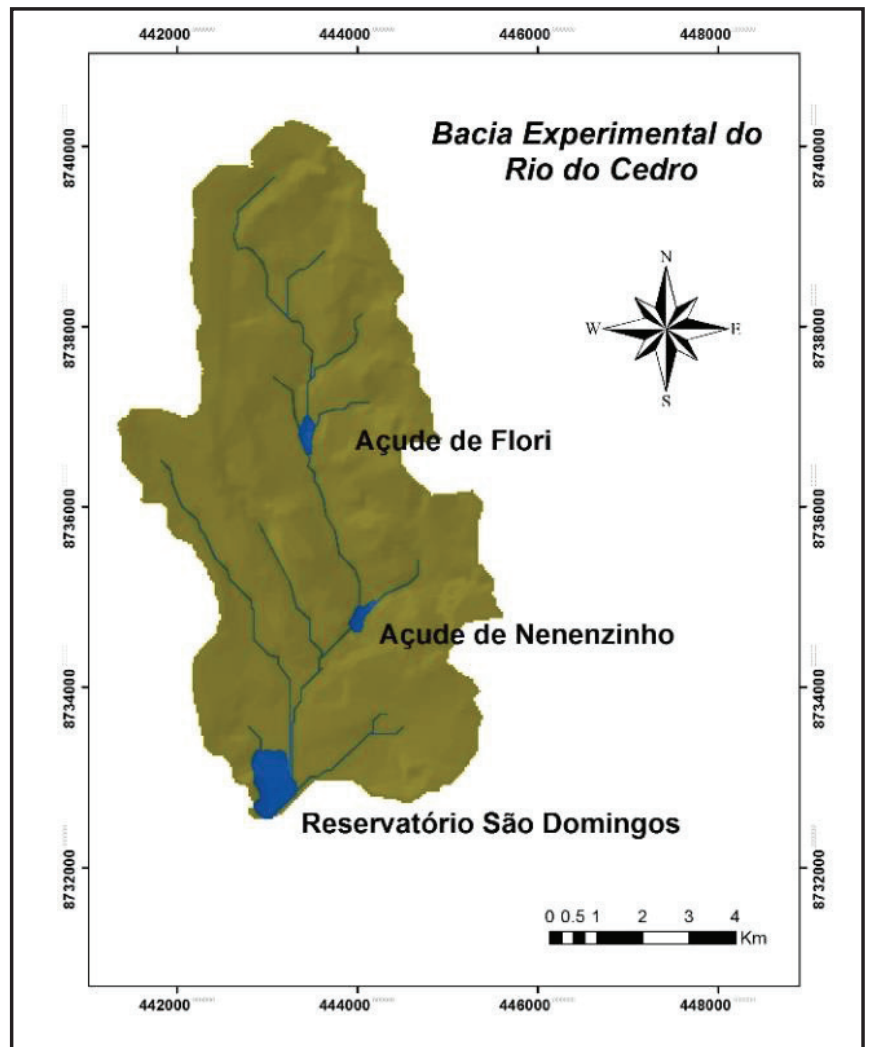

Figura 3 - Localização dos reservatórios na bacia experimental do rio do Cedro

\section{Metodologia}

Para avaliação dos fatores intervenientes do processo de salinização em reservatórios foi realizada comparação de três análises: (i) análise do comportamento hídrico dos reservatórios; (ii) análise da salinidade dos reservatórios; e (iii) análise das características geométrica do lago para cada um dos cinco reservatórios estudados. Para isso foram monitoradas as águas armazenadas,o fluxo de água afluente ao lago e as águas de chuva na área dos reservatórios.

\section{Amostragem}

As amostragens ocorreram durante um ano (de junho de 2006 a setembro de 2007), sendo realizadas cinco campanhas. As Figuras 4 e 5 apresentam a localização dos pontos amostrados para os reservatórios de França e de São José do Jacuípe, respectivamente. O reservatório de França foi amostrado em três pontos ao longo do seu lago (FR3, FR4 e FR5) em seis campanhas de campo e na sua descarga de fundo (FR6) nas quatro últimas campanhas e todo início de mês. Para complementar a análise, foram feitas amostragem em dois pontos a montante (FR1 e FR2), para identificação dos valores isotópicos da água afluente ao lago.

O reservatório de São José do Jacuípe foi monitorado em quatro pontos (SJ2, SJ3, SJ4 e SJ6) e na descarga de fundo (SJ5). O ponto SJ1 é referente ao escoamento afluente ao lago. Para os pontos amostrados no lago de França e São José do Jacuípe foram analisadas duas profundidades (superfície e fundo do reservatório).

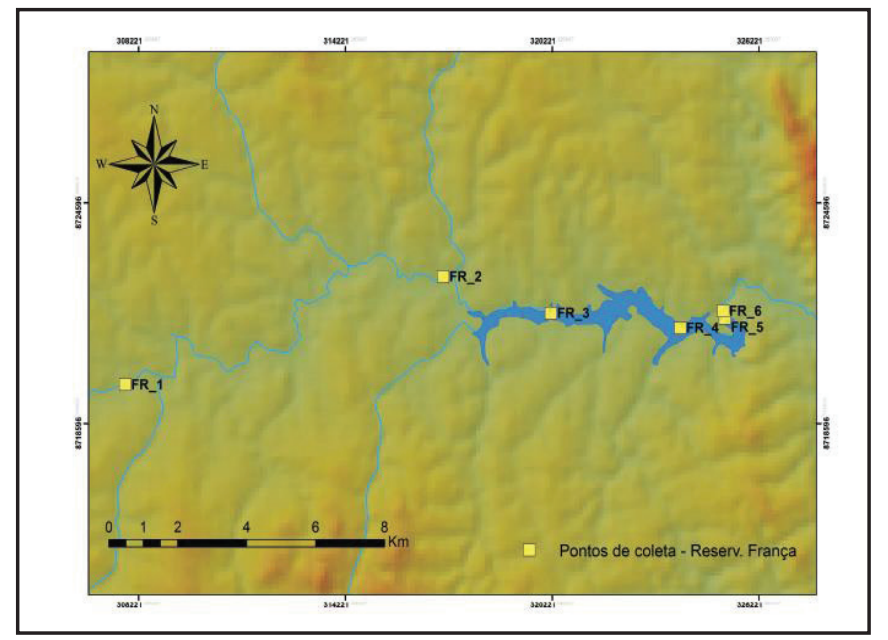

Figura 4 - Pontos amostrados no reservatório de França

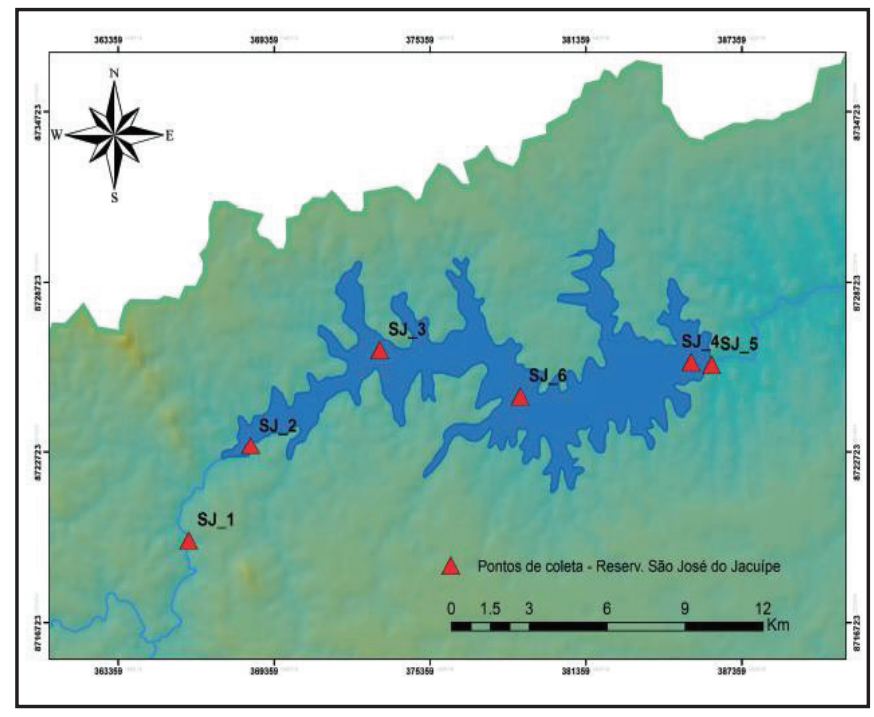

Figura 5 - Pontos amostrados no reservatório de São José do Jacuípe

Nos reservatórios pequenos do rio do Cedro, foi realizado apenas um ponto de amostragem, sendo este próximo ao barramento, sendo que o monitoramento aconteceu mensalmente a partir do mês de outubro de 2006 a dezembro de 2007 para estudos mais detalhados do comportamento hidrológico de pequenos reservatórios do semiárido. $\mathrm{O}$ monitoramento da precipitação foi realizado a nível mensal para todos os reservatórios.

A metodologia utilizada para a coleta e estocagem das amostras referentes à análise isotópica foi orientada de acordo com as instruções da International Atomic Energy AgencyIAEA(IAEA, 2002). O principal cuidado que dever ser tomado é para que não ocorra o fracionamento isotópico, devido à evaporação. Assim, as amostras foram estocadas em frascos âmbar com batoque, completamente preenchidos e guardadas em ambiente refrigerado.

\section{Determinação da razão isotópica da água}

Para as análises isotópicas utilizou-se um sistema de espectrometria de massas contendo: um espectrômetro de massas de razão isotópica (modelo MAT DELTA ${ }^{\text {Plus }}$ da Thermo Finningan) e um reator com injetor automático (H-Device 
Thermo Quest Finnigan), específico para a análise da razão D/H.

Para analisar por espectrometria de massa uma amostra, as moléculas devem estar na forma gasosa. Para isso, as amostras, na forma líquida, passaram por preparações específicas para extrair as moléculas de interesse compatíveis com o sistema de admissão.

A técnica utilizada para a preparação da amostra e determinação dos valores de $\delta^{18} \mathrm{O}$ na água foi a proposta por Epstein e Mayeda (1953), que consiste no equilíbrio isotópico entre o gás carbônico e a água $\left(\mathrm{CO}_{2}-\mathrm{H}_{2} \mathrm{O}\right)$ numa temperatura, geralmente, de $25,0 \pm 0,1^{\circ} \mathrm{C}$ por pelo $18 \mathrm{~h}$ para garantir a reação de equilíbrio isotópico: $\mathrm{H}_{2}{ }^{18} \mathrm{O}+\mathrm{C}^{16} \mathrm{O}^{16} \mathrm{O} \leftrightarrow \mathrm{H}_{2}{ }^{16} \mathrm{O}+\mathrm{C}^{18} \mathrm{O}^{16} \mathrm{O}$.

$\mathrm{O} \mathrm{CO}_{2}$ resultante desse equilíbrio foi extraído para uma linha de purificação de $\mathrm{CO}_{2}$ de alto vácuo onde foram retiradas as impurezas (umidade e gases) sendo posteriormente capturado num porta-amostra e então levado para o espectrômetro de massas.

Para determinar a razão $\mathrm{D} / \mathrm{H}$, foi utilizado o método apresentado por Brandet al. (2000), que propôs a transformação da água em hidrogênio através da redução da água a centenas de graus Celsius com cromo metálico. Alíquotas de $\approx 1,0 \mu \mathrm{l}$ de cada amostra de água são injetadas em um reator, onde ocorre areação de oxidação do cromo a $850^{\circ} \mathrm{C}: 3 \mathrm{H}_{2} \mathrm{O}+2 \mathrm{Cr} \rightarrow \mathrm{Cr}_{2} \mathrm{O}_{3}+3 \mathrm{H}_{2}$.

Obtido o gás de interesse, o mesmo é enviado para a fonte de íons. $\mathrm{Na}$ fonte, os íons são gerados via impacto de elétrons. Os íons formados são detectados em coletores do tipo Faraday posicionados em posições específicas para cada tipo de gás. Num espectrômetro deste tipo a combinação dos campos elétrico e magnético permite selecionar os íons através da razão $\mathrm{m} / \mathrm{q}$.

Como as variações nas abundâncias isotópicas dos isótopos estáveis em processos naturais são muito pequenas é necessária a utilização de uma notação específica. Essa notação, denominada delta, $\delta$, em \%o, por mil, e expressa pela Equação 1.

$$
\delta(\% \mathrm{o})=\frac{\left(R_{\text {amostra }}-R_{\text {pardrão }}\right)}{R_{\text {padrão }}} \times 10^{2}
$$

Onde R é a razão isotópica, entre os isótopos pesados e os mais leves (mais abundantes), ou seja, ${ }^{18} \mathrm{O} /{ }^{16} \mathrm{O}$ e ${ }^{2} \mathrm{H} / \mathrm{H}$, em relação a um padrão. Um valor negativo de $\delta$ significa que a razão do isótopo mais pesado relativamente ao mais leve é menor na amostra que no padrão e um valor de $\delta$ negativo terá o significado oposto (CRAIG, 1957). Esses valores de máquina não são absolutos, portanto, devem ser corrigidos com respeito a um padrão. $\mathrm{O}$ padrão utilizado para água é o VSMOW (Vienna Standard Mean Ocean Water), fornecido pela Agência Internacional de Energia Atômica cujos valores para $\delta \mathrm{D}$ e $\delta^{18} \mathrm{O}$ são definidos como $0 \%$.

Para calibrar as medidas foi analisado juntamente com as amostras, dois padrões secundários, PB1 (água do mar bidestilada) e PB2 (água de cacimba de Irecê-BA) acompanhando cada lote de amostras, com composições isotópicas conhecidas e referenciada em relação ao VSMOW.

Neste caso, todos os valores de delta, dados em relação aos padrões secundários, devem ser convertidos para o seu respectivo padrão universal através da expressão de Craig (1957) dada pela Equação 2.

$$
\delta_{X-A}=\delta_{X-B}+\delta_{B-A}+10^{-3} \cdot\left(\delta_{X-B} \cdot \delta_{X-A}\right)
$$

onde $\delta_{\mathrm{X}-\mathrm{A}}$ é o valor de delta da amostra $\mathrm{X}$, em relação ao padrão $\mathrm{A}$, e $\delta_{\mathrm{X} \text {-B }}$ é o valor de delta da amostra $\mathrm{X}$ em relação ao padrão $\mathrm{B} ; \delta_{\mathrm{B}-\mathrm{A}}$ é o valor de delta do padrão $\mathrm{B}$ em relação ao padrão $\mathrm{A}$. A incerteza associada a essas medidas é da ordem de $1 \%$ para o deutério e $0,1 \%$ para o oxigênio- 18 .

\section{Análise do comportamento hídrico dos reservatórios}

O comportamento de cada reservatório foi avaliado a partir da caracterização da variação temporal dos isótopos do hidrogênio e oxigênio nas águas armazenadas, no fluxo de água afluente ao lago e nas águas de chuva da região. A comparação da assinatura isotópica de cada componente foi utilizada para traçar as interações dos componentes do balanço hídrico nesse manancial e identificar a influência da evaporação nas águas armazenadas. Isso é obtido pela avaliação do empobrecimento ou enriquecimento temporal em isótopos pesados das águas armazenadas e a comparação com a assinatura isotópica da água de chuva e da água afluente.

Para complementar avaliação da ação da evaporação nas águas armazenadas foi utilizado como referencial de comparação de comportamento a Linha Meteórica Global (LMG). Essa linha representa a relação entre o oxigênio-18 e o deutério nas águas naturais mundiais definida por Craig (1961), expressa pela reta apresentada na Equação 3.

$$
\delta \mathrm{D}=8 \delta^{18} \mathrm{O}-10
$$

Esse padrão da composição isotópica da água meteórica proporciona uma referência para a interpretação do caminho percorrido e origem das águas locais e quando comparada com a linha local (obtida a partir de amostras locais) indica a ação da evaporação pela diferença no coeficiente angular da reta. As linhas locais são referentes a água superficial e as águas da chuva local.

A Linha de Evaporação Local -LEL (elaborada a partir das águas superficiais do local em estudo) quando comparada a LMG e a Linha Meteórica Local - LML (elaborada a partir da precipitação do local em estudo) demonstra se a evaporação tem papel importante nas perdas de água dos reservatórios.De acordo Clark e Fritz (1997), se a LEL apresenta uma inclinação menor que a LMG e a LML indica a ação do processo evaporativo nas águas superficiais.Quanto menor for a inclinação da reta em comparação a linha meteórica local configura um ambiente árido com ação da evaporação mais significativa nos rios, reservatórios e lagos.

\section{Análise da salinidade dos reservatórios}

Para análise da evolução da salinidade nas águas superficiais e comparação com as análises isotópicas, as amostras coletadas na bacia do rio Jacuípe foram submetidas às análises químicas com o objetivo de avaliar as propriedades dos sais presente nas águas. Foram determinados a condutividade elétrica e os constituintes iônicos da água que mais frequentemente contribuem para a sua salinização: os cátions sódio, cálcio, magnésio, 
potássio, e os ânions cloreto, carbonato, bicarbonato, sulfato. Esses valores foram comparados com os dados de precipitação da área e com a avaliação do balanço hídrico caracterizado pela razão isotópica. Para os reservatórios maiores foi avaliado valores de condutividade em superfície, profundidade disco secchi e fundo em cada ponto de coleta.

\section{Análise das características geométrica do lago}

Para definição das características dessa geometria considerou-se que, a relação entre a profundidade e o volume do açude pode ser obtida pela Equação de Molle e Cadier (1992) para o semiárido:

$$
V=K \times H^{\alpha}
$$

onde: $\quad \mathrm{V}$ - volume armazenado pelo açude;

$\mathrm{H}$ - altura do nível de água do açude;

$\alpha$ - coeficiente de forma das curvas das encostas do açude;

$\mathrm{K}$ - coeficiente de abertura e representa o caráter mais ou menos "aberto" do açude.

Estes autores afirmam que, em geral, no semiárido brasileiro os valores de $\mathrm{K}$ variam de 200 a 10.000 , indicando vale encaixado e vale aberto, respectivamente. $E$ os valores de $\alpha$ variam de 2,20 a 3,40 indicando encostas côncavas a encostas convexas. Estes parâmetros foram calculados para os reservatórios em estudo, exceto para o São Domingos por indisponibilidade de dados.

\section{RESULTADOS E DISCUSSÃO}

\section{Análise do comportamento hídrico dos reservató-} rios por meio da caracterização isotópica

\section{Reservatório de França}

De acordo com a caracterização da evolução espaçotemporal dos isótopos dos seis pontos de amostragem referente ao monitoramento do reservatório de França verifica-se pela variação do $\delta \mathrm{D}(\%)$ e do $\delta^{18} \mathrm{O}(\%)$ a tendência de enriquecimento em isótopos pesados nos períodos secos e empobrecimento desses no período chuvoso, mostrando a influência da evaporação nas águas armazenadas. Os pontos localizados no lago (FR3, FR4 e FR5) têm comportamento similar, mostrando que o reservatório apresenta água mais influenciada pela evaporação que as águas que afluem ao reservatório (FR1 e FR2) no período seco $(10 / 12 / 2006)$. A Figura 6 apresenta o comportamento do $\delta \mathrm{D}$ $(\%)$, ressalvando que o $\delta^{18} \mathrm{O}(\%)$ se comportou com o mesmo padrão de variação.

Com a ocorrência das chuvas intensas do mês de fevereiro de 2007, as águas mais superficiais armazenadas no lago ficaram negativas, da ordem dos valores encontrados para a chuva ocorrida $(\delta \mathrm{D}=-33 \% 0)$, tornando a água armazenada no reservatório mais negativa que as águas de escoamento superficial de sua área de drenagem, em março de 2007. Apenas a descarga de fundo apresentou valores mais positivos indicando que em março não havia ocorrido uma mistura completa das águas do

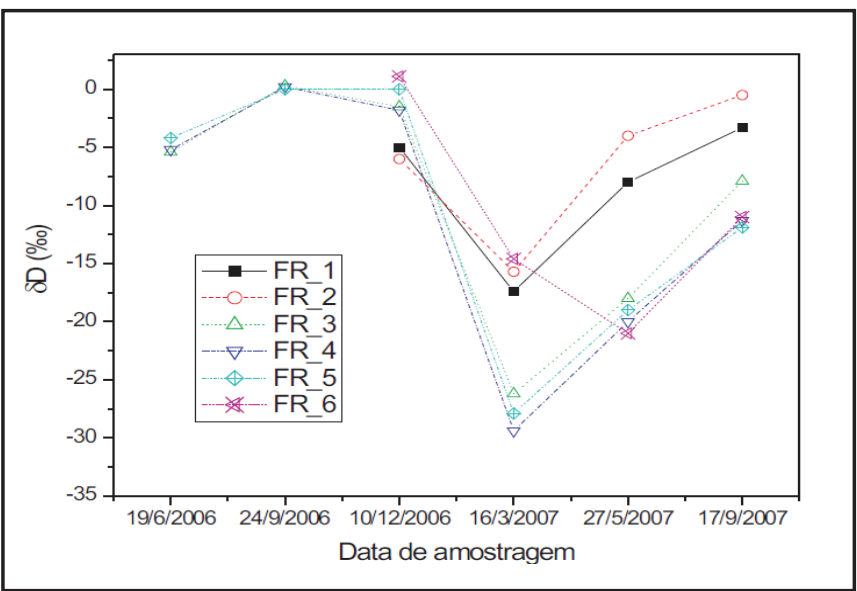

Figura 6 - Variação temporal do $\delta \mathrm{D}$ no Reservatório de França

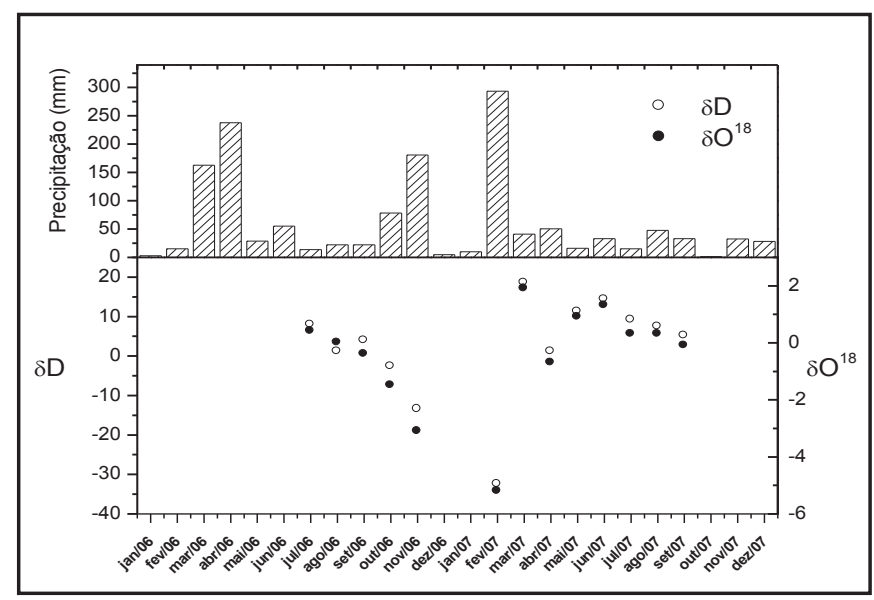

Figura 7 - Precipitação mensal em França e variação temporal da composição isotópica

reservatório, o que foi verificado na próxima campanha, em maio de 2007. Ainda nesse mês o reservatório conserva a característica isotópica mais negativa que as águas de escoamento.

Em setembro de 2007, verifica-se um enriquecimento significativo das águas armazenadas, na ordem de $10 \%$ para o $\pm \delta \mathrm{D}$, proveniente: das perdas de água por evaporação, das águas de escoamento mais positivas que continuaram afluindo ao lago ( $\delta \mathrm{D}>-5 \%$ ) e por contribuição direta das chuvas do período que se caracterizam por valores isotópicos positivos $(\delta \mathrm{D}=+5 \%$ ). A influência da vazão de entrada é percebida pela elevação dos valores encontrados para o ponto FR3 após a ocorrência da chuva, em contraponto ao período anterior.

Pela linha de evaporação local (LEL) do reservatório de França, igual a $\delta \mathrm{D}=6.63 \delta^{18} \mathrm{O}-0.773$, calculada considerando os pontos do lago e a descarga de fundo do reservatório e comparada com a LMG, verifica-se que as águas do reservatório sofrem ação da evaporação característica de ambientes mais áridos (coeficiente angular menor que 8). A Figura 8 exemplifica essa comparação.

A linha meteórica das chuvas (LML) ocorridas na área do reservatório de França, considerando as de grande intensidade (responsáveis pelo enchimento do reservatório) apresenta coeficiente angular igual a 8,1, próximo ao da LMG. A diferença dos coeficientes confirma a ação da evaporação nas águas da bacia 


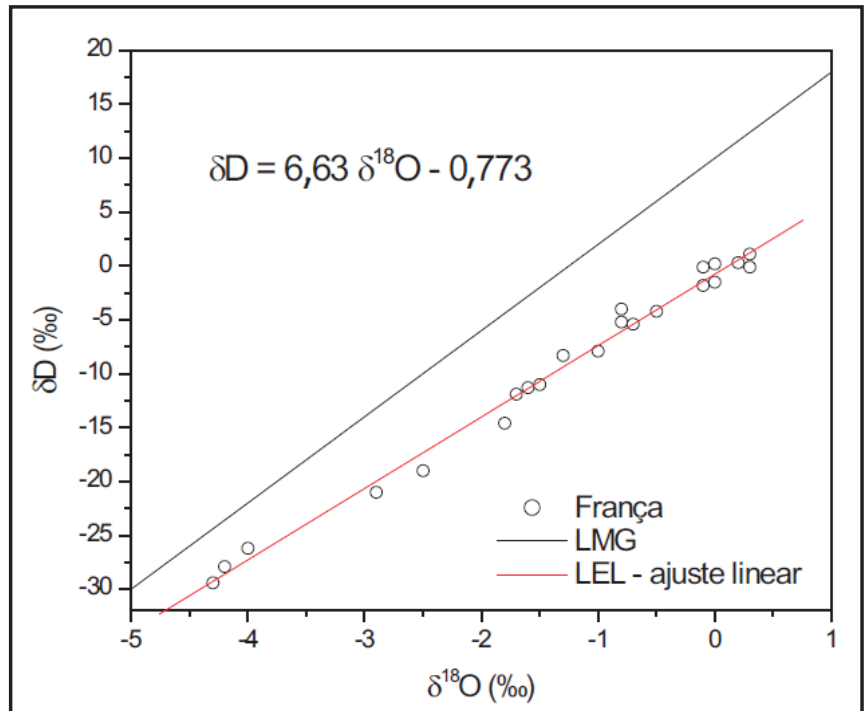

Figura 8 - Comparação da Linha de Evaporação Local e Linha Meteórica Global para o Reservatório de França

de drenagem desse reservatório, seja pela evaporação das águas armazenadas, como pela evaporação das águas do escoamento superficial associadas às perdas pela evaporação secundária das águas de chuva na ocasião de sua ocorrência.

De acordo com esses valores, caracteriza-se o comportamento hídrico do reservatório de França como dinâmico. Esse comportamento possibilita mistura e renovação da água armazenada na ocorrência de chuvas intensas aliado a significativa influência da evaporação.

\section{Reservatório de São José do Jacuípe}

De acordo com a caracterização da evolução espaçotemporal dos isótopos dos seis pontos de amostragem referente ao monitoramento do reservatório de São José do Jacuípe (Figura 9) verifica-se nos pontos mais a montante do lago (SJ2 e SJ3) que a composição isotópica reflete os valores encontrados para as vazões de entrada (SJ1), o que não é observado para o ponto próximo ao barramento (SJ4). Este ponto permaneceu estável durante as três primeiras amostragens, antes das chuvas de fevereiro de 2007.

Como as águas afluentes ao reservatório trazem valores

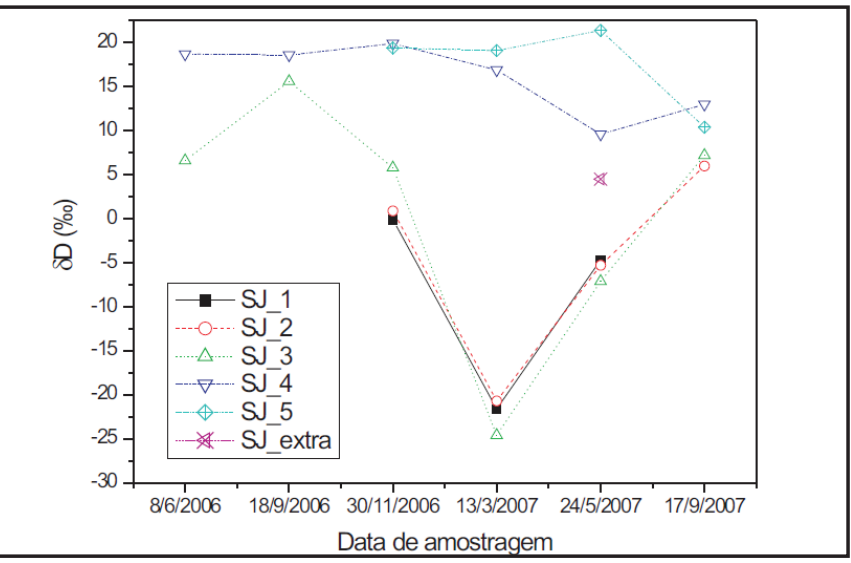

Figura 9 - Variação temporal do $\delta \mathrm{D}$ no Reservatório de São José do Jacuípe isotópicos mais negativos.Isso indica que o enriquecimento pela evaporação é compensado por elas, que vão entrando gradativamente no reservatório. As amostras de novembro de 2006 para os pontos SJ4 e SJ5 apresentam valores coincidentes, configurando uma homogeneidade entre a superfície e o fundo em relação a águas afetadas pela evaporação. Após o período da chuva, o início do lago continua com seus valores isotópicos próximos aos da vazão afluente (SJ1, SJ2 e SJ3), enquanto as águas próximas ao barramento apresentam uma pequena redução ( $2 \%$ no $\delta \mathrm{D}$ ) em março. Um empobrecimento de $7 \%$ no $\delta \mathrm{D}$ foi verificado na campanha de maio de 2007, indicando que SJ4 passa a receber contribuições das águas de escoamento de sua área de drenagem. As águas liberadas pela descarga de fundo são também enriquecidas e só apresentaram mudanças no seu valor isotópico cerca de seis meses após o evento de chuva intensa (período entre fevereiro e setembro).

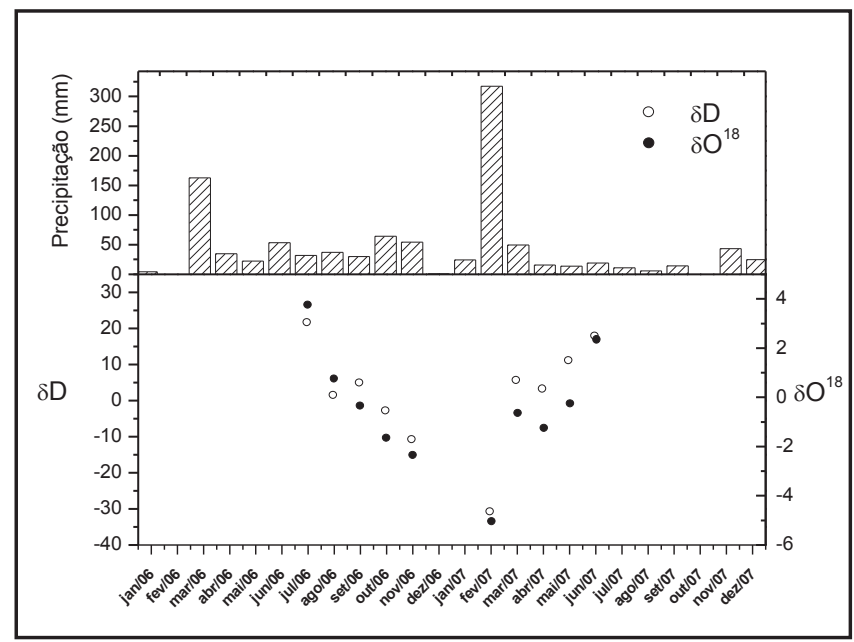

Figura 10 - Precipitação mensal na região de São José do Jacuípe e variação temporal da composição isotópica

O reservatório de São José restitui ao rio Jacuípe águas caracterizadas por valores isotópicos positivos que refletem a significativa ação da evaporação. Assim como no reservatório do França, cabe observar que, uma vez que as águas armazenadas em São José do Jacuípe são também predominantemente influenciadas pelas chuvas intensas e que as chuvas de baixa intensidade não variam a composição isotópica dessas águas do lago, fica mais evidente a ocorrência da evaporação das águas dos reservatórios realizando a comparação da linha de evaporação local desse reservatório com a linha meteórica relativa às chuvas ocorridas (LML) no período que tem inclinação de 7,9, próxima à da LMG.

A linha de evaporação local que reflete as águas afetadas pela evaporação apresentou coeficiente angular (inclinação) de 5,7, inferior a LML. De acordo com esse coeficiente esse reservatório apresenta águas mais afetadas pela evaporação do que o reservatório de França.

De acordo com os valores isotópicos, o lago de São José do Jacuípe apresenta águas afetadas pela evaporação principalmente nos pontos mais próximos ao barramento e nas águas que saem pela descarga de fundo. A renovação e mistura da água não são identificadas pelos valores isotópicos, sendo 
que apenas no mês de setembro (6 meses após a ocorrência da chuva mais intensa), verifica-se uma proximidade dos valores dos pontos amostrados, convergente para valores próximos a $+10 \%$ para o $\delta \mathrm{D}$. Este fato é coerente com sua localização em área mais árida que o reservatório do França e dimensões maiores, não apresentando renovação de suas águas.

\section{Reservatórios de São Domingos, Nenezinho e Flori}

A evolução temporal dos valores dos isótopos da água nos três reservatórios da bacia experimental está apresentada na Figura 11 para o $\delta \mathrm{D}(\% 0)$. $\mathrm{O} \delta^{18} \mathrm{O}(\% 0)$ seguiu o mesmo padrão de variação. A Figura 12 apresentaa variação temporal da chuva e sua composição isotópicas em São Domingos.

A comparação entre essa evolução temporal do comportamento do $\delta \mathrm{D} \%$ e e as chuvas mensais no período demonstra que o comportamento dos reservatórios apresenta forte correlação com a variabilidade climática local, ou seja, na ocorrência de chuvas intensas os reservatórios menores (Nenenzinho e Flori) renovam suas águas e passam a ter a composição isotópica da chuva $(\delta \mathrm{D}=-49 \%$ ) e o reservatório fica com aguas apresentando

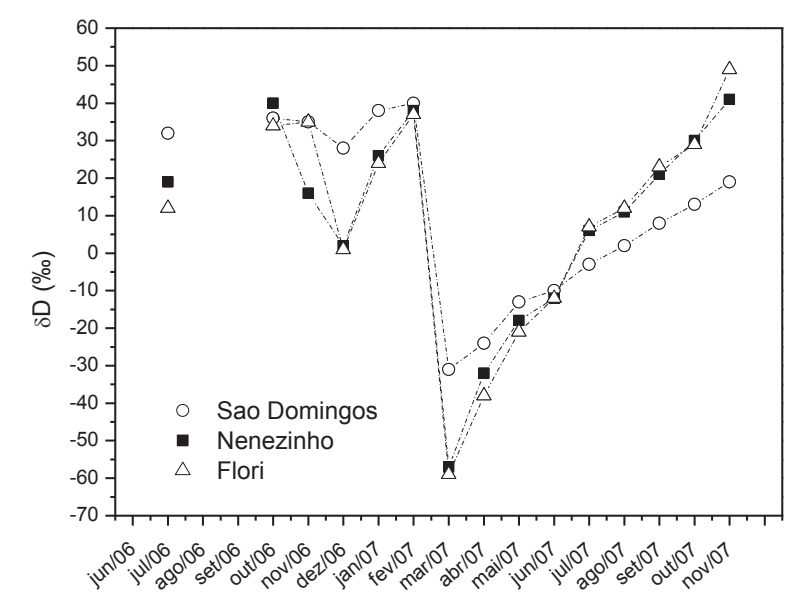

Figura 11 - Evolução temporal do $\delta \mathrm{D} \%$ na bacia experimental

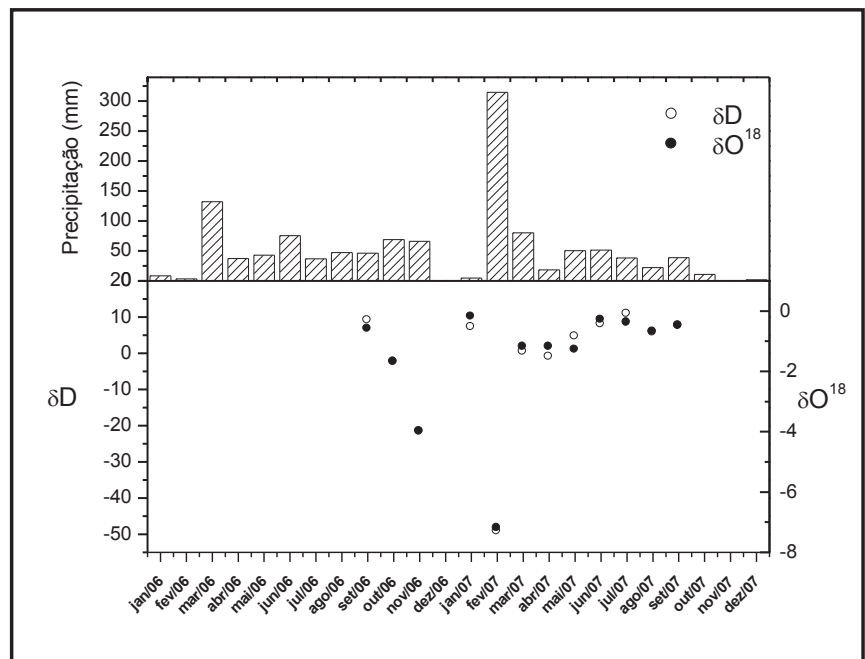

Figura 12 - Precipitação total mensal e valores isotópicos - São Domingos (2006-2007) valores isotópicos próximos. Com a ação da evaporação essas águas vão se tornando enriquecidas em isótopos pesados. Para a ocorrência de chuvas menos intensas porem negativas $(\delta \mathrm{D}=$ $22 \%$ em novembro de 2006 ) verifica-se uma leve variação na composição das águas armazenadas. No período seco os valores isotópicos de suas águas se tornam mais positivos devido a evaporação.

Percebe-se, entretanto, uma diferença entre o reservatório de São Domingos, de maior dimensão e os outros dois, o qual apresenta um comportamento mais estável e águas parcialmente renovadas com a chuva de fevereiro de 2007. Entre os reservatórios de Nenenzinho e Flori, apesar deste último ter um terço do volume armazenado que o Nenenzinho, não é verificada diferenças relativas ao comportamento isotópico frente à ocorrência de chuva e ao processo de evaporação.

A LML apresentou comportamento representado pelo coeficiente angular igual a 8,4, enquanto as LEL apresentaram esse coeficiente próximo a 6 , confirmando a ação significativa da evaporação quando essa água fica armazenada em reservatórios superficiais. Entretanto cabe ressaltar que comparando a linha de evaporação (LEL) para cada reservatório apresentadas na Tabela 1, tem-se uma menor inclinação para o menor reservatório, sugerindo que suas águas são mais afetadas pelos processos de evaporação.Outro fator importante de ser avaliado é a inércia da massa de água frente a esse processo, uma vez que o reservatório de São Domingos tem suas águas menos afetadas pelo processo de evaporação. Essa afirmação do menor reservatório ter apresentado águas mais afetadas pela evaporação foi confirmada por Fontes (2008) que estimou as perdas de evaporação desses três reservatórios utilizando os isótopos estáveis aplicados ao modelo de destilação de Rayleigh (evaporação real) para o período de julho a outubro de 2007 e validou os resultados com ao método de Penman (evaporação potencial). Foi calculada a fração remanescente total para novembro do volume armazenado, obtendo-se o valor de 0,77 para o São Domingos, 0,66 para o Nenenzinho e 0,60 para o Flori, o que representa para este último uma taxa de evaporação de $40 \%$ do volume armazenado em apenas quatro meses.

LML

Tabela 1 - Valores ajustados do $\delta \mathrm{D}(\%)$ x $\delta \mathbf{O} 18(\%)$ para os reservatórios da bacia experimental

\begin{tabular}{c|c|c}
\hline Reservatórios & Ajuste linear & $\mathrm{R}$ \\
\hline São Domingos & $(6,9 \pm 0,2) \cdot \delta \mathrm{O}^{18}-(12 \pm 1) \% 0$ & 0,99 \\
\hline Flori & $(6,2 \pm 0,3) \cdot \delta \mathrm{O}^{18}-(13 \pm 2) \% 0$ & 0,98 \\
\hline Nenenzinho & $(6,4 \pm 0,3) \cdot \delta \mathrm{O}^{18}-(13 \pm 2) \% 0$ & 0,99 \\
\hline
\end{tabular}

\section{Análise da salinidade dos reservatórios}

\section{Reservatório de França}

A Tabela 2 apresenta os valores de condutividade elétrica das amostras do Reservatório de França para as seis campanhas realizadas no período de estudo.

De acordo com as análises químicas dos pontos amostrados no reservatório de França relativo aos sais presentes na 
Fontes et al.: Avaliação dos fatores intervenientes no processo de salinização em reservatórios superficiais do semiárido brasileiro

Tabela 2 - Condutividade elétrica $\left(\mu \mathrm{S} . \mathrm{cm}^{-1}\right)$ das amostras do Reservatório de França em superfície, profundidade disco secchi e fundo

\begin{tabular}{|c|c|c|c|c|c|c|}
\hline Pontos & $\begin{array}{c}\text { C1 } \\
\text { jun/ } \\
06\end{array}$ & $\begin{array}{c}\text { C } 2 \\
\text { set/ } \\
06 \\
\end{array}$ & $\begin{array}{c}\text { C } 3 \\
\text { dez/ } \\
06\end{array}$ & $\begin{array}{c}\mathrm{C} 4 \\
\text { mar/ } \\
07\end{array}$ & $\begin{array}{c}\text { C } 5 \\
\text { mai/ } \\
07\end{array}$ & $\begin{array}{c}\mathrm{C} 6 \\
\text { set/ } \\
07 \\
\end{array}$ \\
\hline \multicolumn{7}{|c|}{ Condutividade $\left(\mu \mathrm{S} . \mathrm{cm}^{-1}\right)$ - Superfície } \\
\hline FR1 & 221 & 341 & 134 & 197 & 550 & 487 \\
\hline FR2 & 259 & 282 & 127 & 492 & 644 & 596 \\
\hline FR3 & 162 & 187 & 199 & 229 & 276 & 321 \\
\hline FR4 & 162 & 184 & 176 & 192 & 249 & 292 \\
\hline FR5 & 162 & 188 & 192 & 134 & 243 & 283 \\
\hline FR6 & 171 & 118 & 194 & 679 & 242 & 297 \\
\hline \multicolumn{7}{|c|}{$\begin{array}{c}\text { Condutividade }\left(\mu \mathrm{S} . \mathrm{cm}^{-1}\right) \text { - Profundidade Disco } \\
\text { Secchi }\end{array}$} \\
\hline FR3 & 161 & 188 & 193 & 229 & 276 & 321 \\
\hline FR4 & 162 & 183 & 186 & 196 & 249 & 288 \\
\hline FR5 & 162 & 187 & 187 & 118 & 243 & 283 \\
\hline \multicolumn{7}{|c|}{ Condutividade $\left(\mu \mathrm{S} . \mathrm{cm}^{-1}\right)$ - Fundo } \\
\hline FR3 & 162 & 185 & 161 & 437 & 333 & 306 \\
\hline FR4 & 163 & 170 & 195 & 173 & 248 & 269 \\
\hline FR5 & 166 & 168 & 197 & 210 & 249 & 268 \\
\hline
\end{tabular}

água, verifica-se que em junho de 2006 o lago apresentou os menores valores de salinidade do período analisado, sem estratificação em relação a profundidade e valores de condutividade em torno de $160 \mu \mathrm{S} . \mathrm{cm}^{-1}$. Os pontos a montante do reservatório, que representam a qualidade da água que aflui ao lago, apresentaram teores mais elevados. Esse comportamento se repete na campanha seguinte com uma pequena elevação $\left(187 \mu \mathrm{S} . \mathrm{cm}^{-1}\right)$ nos valores do lago, devido à contribuição da vazão do rio e da concentração dos sais pela evaporação das águas armazenadas, indicada pelos valores isotópicos. O ponto FR1 apresenta uma elevação na condutividade pela vazão recebida do rio Jacuípe (de $221 \mu \mathrm{S} . \mathrm{cm}^{-1}$ para $341 \mu \mathrm{S} . \mathrm{cm}^{-1}$ ), que tem aumento devido a contribuições predominantes de água subterrânea nos períodos mais secos, conforme indica os valores isotópicos em Fontes (2011). A amostragem seguinte ocorreu em dezembro, após período de chuvas empobrecidas isotopicamente, o que levou a uma diluição dos sais em FR2 (127 $\left.\mu \mathrm{S} . \mathrm{cm}^{-1}\right)$, mas sem alteração no lago. Em fevereiro as chuvas foram intensas provocando escoamentos superficiais em toda a bacia, alimentando os afluentes até então secos. Entre os pontos FR1 e FR2 verificou-se a contribuição do escoamento do afluente da margem esquerda do Jacuípe, já no domínio cristalino, com aporte de sais causando uma elevação na condutividade $\left(492 \mu \mathrm{S} . \mathrm{cm}^{-1}\right)$. Nessa campanha também foi observado no ponto FR3 um aumento na condutividade de $30 \mu \mathrm{S} . \mathrm{cm}^{-1}$ na superfície e de $276 \mu \mathrm{S} . \mathrm{cm}^{-1}$ no fundo, apesar da contribuição da chuva do período. Isso indica aporte de sal ao lago. O mesmo comportamento foi observado no FR4.

No ponto FR5 (mais próximo ao barramento) houve redução dos níveis de salinidade de $192 \mu$ S.cm ${ }^{-1}$ para $134 \mu$ S.cm ${ }^{-1}$ com o aporte da água pluvial, exceto no fundo que passou para $210 \mu \mathrm{S} . \mathrm{cm}^{-1}$, indicando que não houve renovação.

O ponto FR6 (descarga de fundo) confirma a existência de sais no solo, uma vez que, com a ocorrência do escoamento superficial nas proximidades do local da amostragem,as águas desse ponto têm a condutividade elevada a níveis próximos da classificação salobra $\left(679 \mu \mathrm{S} . \mathrm{cm}^{-1}\right)$. Na campanha de março/2007 a amostra coletada nesse ponto, devido ao volume do escoamento superficial e formação de um lago a jusante da barragem, descaracteriza a água proveniente da descarga de fundo, conforme é verificado nas demais campanhas quando não há essa contribuição de escoamento lateral.

As amostras de maio de 2007 revelam a capacidade da área de drenagem em contribuir com o processo de aporte de sais ao reservatório, uma vez que é verificada no ponto FR1 uma variação de $350 \mu \mathrm{S} . \mathrm{cm}^{-1}$ na condutividade, que representa a contribuição do próprio rio Jacuípe e no ponto FR2 com valores ainda mais elevados que representa a contribuição do afluente desse trecho. Nessa campanha ainda foi percebida a presença de águas com condutividade mais elevada no fundo do reservatório no ponto FR3 $\left(333 \mu \mathrm{S} . \mathrm{cm}^{-1}\right.$ no fundo e $276 \mu{\mathrm{S} . \mathrm{cm}^{-1}}^{-1}$ na superfície, o que cessa na campanha seguinte em setembro de 2007, os valores ficam próximos a $310 \mu \mathrm{S} . \mathrm{cm}^{-1}$.

Comparando os valores das campanhas de setembro de 2006 a setembro de 2007, período de um ano hidrológico da região caracterizado por ocorrência de chuvas intensas concentradas em um curto período de tempo, acompanhando a variabilidade climática característica de regiões do semiárido, verifica-se que houve um incremento da condutividade no reservatório, apesar dele receber predominantemente águas doces proveniente de sua área de drenagem e ter dimensões que possibilitam a renovação do volume armazenado.

A análise do balanço iônico do escoamento de entrada ao lago do reservatório, ponto FR2, mostra que a contribuição da área de drenagem se dá com aporte prioritariamente de cloretos e sódio, em concentrações adequadas para consumo humano. A evolução temporal desses íons, apresentada na Figura 13, confirma o maior aporte de sais no período chuvoso, com uma defasagem de aproximadamente dois meses do evento de chuvas intensas, período que as chuvas infiltram no solo atingindo as camadas mais subsuperficiais e carreiam os sais para o leito dos rios.

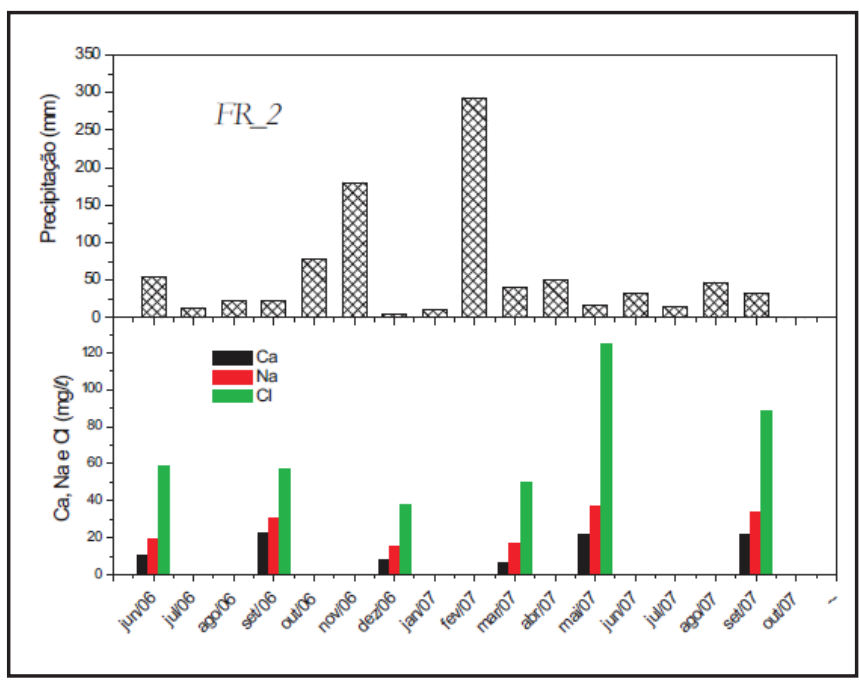

Figura 13 - Evolução temporal dos ions $\mathrm{Ca}$, Na e $\mathrm{Cl}$ - vazão afluente ao reservatório de França (FR2) 
Analisando o ponto FR5 do reservatório, percebe-se a rápida resposta das águas armazenadas: a entrada de sais e seguida de diluição e posterior elevação no nível de concentrações de sais, após a ocorrência de eventos intensos de chuva, conforme pode ser observado na Figura 14 que apresenta a evolução dos íons cloreto, sódio e cálcio no lago do França ao longo do tempo.

A resposta rápida do reservatório para a vazão de entrada (representada pelo ponto FR2), com uma pequena defasagem de tempo na elevação da concentração de cloreto, indica que este fato ocorrido em maio de 2007 no lago foi proveniente predominantemente da qualidade da água do escoamento afluente, sem interferência significativa da evaporação como agente concentrador.

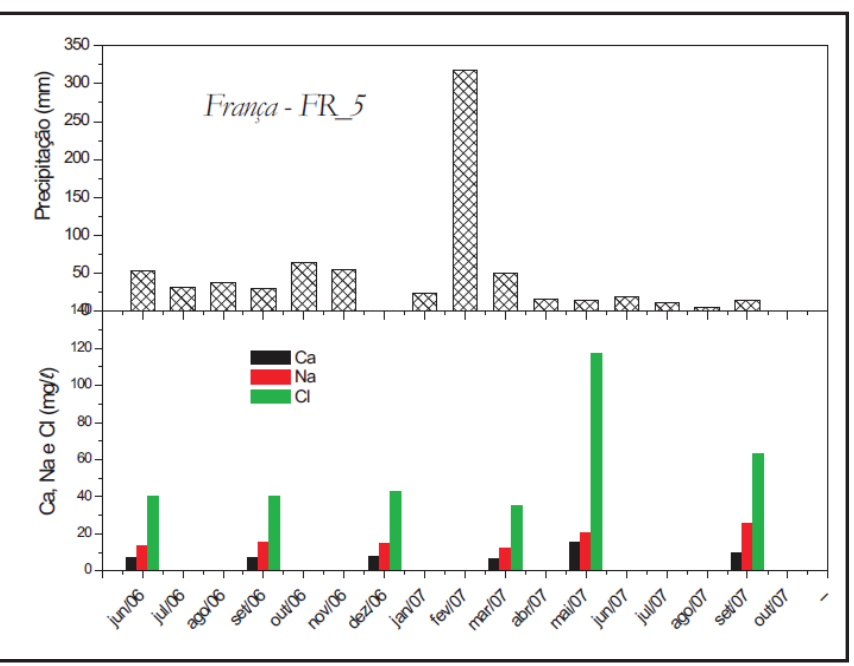

Figura 14 - Evolução temporal dos íons $\mathrm{Ca}, \mathrm{Na}$ e $\mathrm{Cl}$ - reservatório de França (FR5)

No reservatório de França, por ter suas águas exposta a evaporação, há um comportamento diferenciado para os períodos antes e depois da ocorrência de chuva, apresentando para o primeiro período a influência da evaporação das águas e, para o período após chuva intensa, contribuição da vazão do afluente que apresenta concentrações de sais elevadas na sua calha.

\section{Reservatório de São José do Jacuípe}

A Tabela 3 apresenta os valores de condutividade elétrica das amostras do Reservatório de São José do Jacuípe para as seis campanhas realizadas no período de estudo.

Este reservatório armazena águas salobras, com significativa variação nas concentrações de sais ao longo do lago. Em junho de 2006, os pontos SJ1, SJ2 e SJ3, na superfície e fundo, apresentavam condutividade similar, na ordem de $1100 \mu \mathrm{S} . \mathrm{cm}^{-1}$, havendo um aumento de mais de $100 \%$ para o ponto SJ4, nas duas profundidades avaliadas. Confirma-se a forte influência da vazão (SJ1) do rio nos dois primeiros pontos do lago, verificada nas análises isotópicas. Na segunda campanha houve uma diluição nas concentrações de sais na vazão de entrada que refletiu apenas no ponto SJ2 $\left(630 \mu \mathrm{S} . \mathrm{cm}^{-1}\right)$, já o ponto SJ3 ficou mais salobro $\left(1773 \mu \mathrm{S} . \mathrm{cm}^{-1}\right)$. Os dados isotópicos entre as duas campanhas mostram um enriquecimento significativo nesse ponto SJ3, indicando o efeito da evaporação no aumento da salinidade. $\mathrm{O}$
Tabela 3 - Condutividade elétrica $\left(\mu \mathrm{S} . \mathrm{cm}^{-1}\right)$ das amostras do Reservatório de São José do Jacuípe em superfície, profundidade disco secchi e fundo.

\begin{tabular}{c|c|c|c|c|c|c}
\hline Pontos & $\begin{array}{c}\text { C1 } \\
\text { jun/ } \\
06\end{array}$ & $\begin{array}{c}\text { C 2 } \\
\text { set/ } \\
06\end{array}$ & $\begin{array}{c}\text { C 3 } \\
\text { dez/ } \\
06\end{array}$ & $\begin{array}{c}\text { C 4 } \\
\text { mar/ } \\
07\end{array}$ & $\begin{array}{c}\text { C 5 } \\
\text { mai/ } \\
07\end{array}$ & $\begin{array}{c}\text { C 6 } \\
\text { set/ } \\
07\end{array}$ \\
\hline \multicolumn{7}{c}{ Condutividade $\left(\mu\right.$ S.cm $\left.^{-1}\right)$ - Superfície } \\
\hline SJ1 & 1142 & 596 & 869 & 1124 & 2085 & 1297 \\
\hline SJ2 & 1149 & 630 & 847 & 1184 & 2228 & 1473 \\
\hline SJ3 & 1184 & 1773 & 1744 & 680 & 1328 & 1671 \\
\hline SJ4 & 2430 & 2380 & 2469 & 2161 & 1939 & 1808 \\
\hline SJ5 & 2440 & 2339 & 2352 & 2255 & 2357 & 1804 \\
\hline Condutividade $\left(\mu S^{-1}\right)$ & - Profundidade Disco Secchi \\
\hline SJ2 & 1148 & & 847 & 1183 & 2184 & 1469 \\
\hline SJ3 & 1184 & 1770 & 1744 & 681 & 1323 & 1671 \\
\hline SJ4 & 2430 & 2340 & 2453 & 2158 & 1928 & 1809 \\
\hline \multicolumn{7}{c}{ Condutividade $(\mu$ S.cm -1$)-$ Fundo } \\
\hline SJ2 & 1146 & 624 & 848 & 1172 & 2169 & 1458 \\
\hline SJ3 & 1182 & 1769 & 1774 & 990 & 1284 & 1672 \\
\hline SJ4 & 2420 & 2301 & 2337 & 2314 & 2294 & 1798 \\
\hline
\end{tabular}

ponto SJ4 mantém o mesmo comportamento da coleta anterior. Diferenças significativas nas concentrações só são percebidas em março de 2007, após a ocorrência das chuvas, quando os valores de condutividade têm: um incremento de cerca de 270 $\mu \mathrm{S} . \mathrm{cm}^{-1}$ para a vazão afluente e o ponto SJ2.

Em maio de 2007, percebe-se uma elevação da condutividade em $340 \mu \mathrm{S} . \mathrm{cm}^{-1}$ para o ponto SJ2 em resposta à contribuição do escoamento superficial, que traz os íons carreados dos solos e dos afluentes. Já nos pontos SJ3 e SJ4 há uma redução nos valores de condutividade em $1064 \mu$ S.cm ${ }^{-1}$ e 309 $\mu \mathrm{S} . \mathrm{cm}^{-1}$ respectivamente, devido à mistura com a vazão afluente que apesar de incrementada com sais ainda teve características menos salobra que a água armazenada. O ponto referente à descarga de fundo do reservatório (SJ5) não apresenta variações significativas.

Em setembro de 2007 a contribuição dos afluentes já cessou, havendo uma redução nos valores de condutividade na vazão de entrada, entretanto, há uma elevação nos teores de sais para o ponto SJ3, retornando a níveis próximos ao encontrado para o mesmo período de 2006. O ponto SJ4 e SJ5, nessa coleta também apresentam redução na condutividade após a mistura das águas. Cabe observar, entretanto, que o aporte de sal ao longo do tempo se elevou após o evento de chuva, de um ano para outro. Esse resultado reforça a afirmação apresentada por SRH-BA (2007), que o processo de salinização do reservatório não foi revertido, está em franco avanço.

A análise do balanço iônico da vazão de entrada ao lago do reservatório pela Figura 15, ponto SJ1, mostra que o cloreto é o íon predominante e o aporte de sais é superior aos limites recomendados para consumo humano, se elevando no mês de abril após a ocorrência de eventos intensos de chuva em fevereiro. A elevação da concentração dos íons principais, aproximadamente dois meses após a ocorrência de chuvas intensas, reforça a indicação que o aporte de sais nesse período é devido ao escoamento subsuperficial que lava os sais presente 


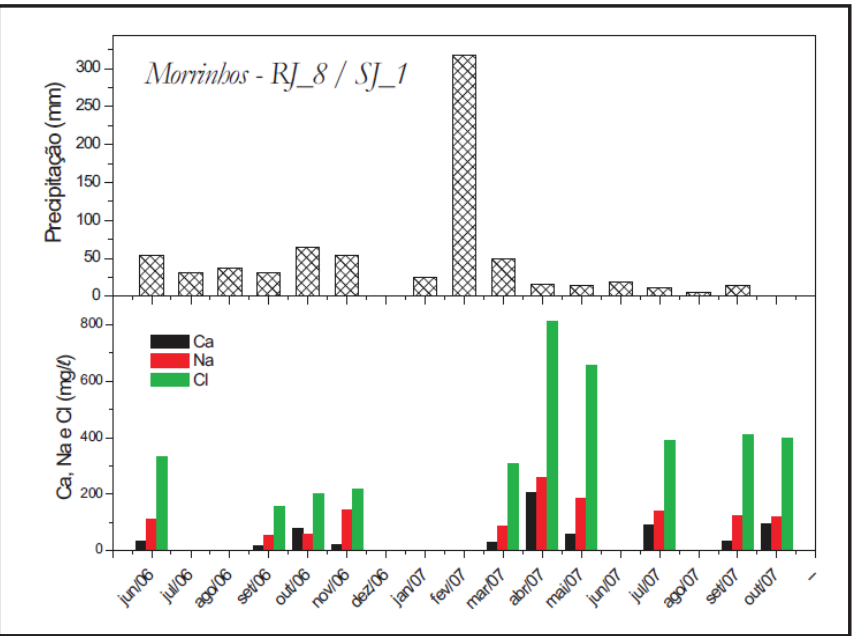

Figura 15 - Evolução temporal dos íons $\mathrm{Ca}, \mathrm{Na}$ e $\mathrm{Cl}$ - vazão afluente ao reservatório de São José do Jacuípe (SJ1)

em camadas mais profundas do solo. Após o pico de concentração em abril, no mês seguinte, sem ocorrência significativa de chuva, as concentrações dos íons decrescem e se tornam estáveis, com aumento a partir do mês de setembro pela ação da evaporação, processo identificado com a análise dos valores isotópicos nesse período.

A Figura 16 mostra o comportamento das águas da superfície do ponto SJ4. O reservatório de São José possui concentrações de cloreto superiores ao recomendado para consumo humano(250 mg/l) e de sódio no limite de recomendação (200 mg/l) pela Portaria No 2.914/2011 do Ministério da Saúde, apresentando uma redução após a contribuição direta da chuva de fevereiro de 2007. Entretanto, retoma o crescimento em setembro de 2007 com a contribuição do escoamento superficial e efeitos da evaporação.

A partir da análise dos valores isotópicos no ponto SJ4, foi identificado que existe um tempo de aproximadamente quatro meses para as águas do escoamento afluente proveniente das chuvas de fevereiro atingir esse ponto. O que ocorre a partir de junho, e é após esse período (campanha de setembro de 2007) que se observa o aumento da concentração, salientando o papel dessas águas afluentes no aumento da salinidade entre

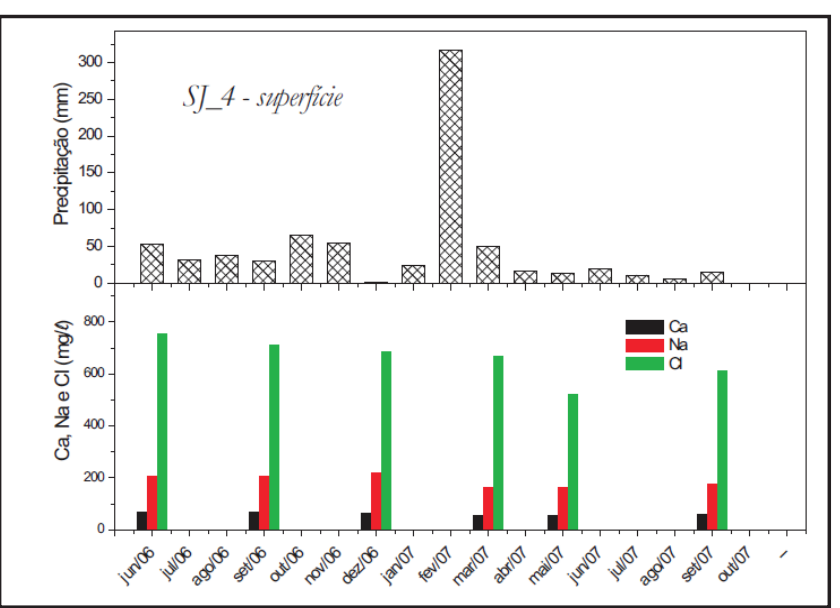

Figura 16 - Evolução temporal dos ions $\mathrm{Ca}, \mathrm{Na}$ e $\mathrm{Cl}$ - reservatório de São José do Jacuípe (SJ4) as campanhas de maio e setembro de 2007.

No reservatório de São José verificam-se dois processos de variação na concentração dos sais: um direto no lago do reservatório pela evaporação e diluição da chuva e o outro pela entrada da vazão afluente mais salgada. Essa diferenciação ainda é significativa se for analisado separadamente o período antes e depois da chuva.

Outro ponto de análise é a presença do reservatório de França, a montante, que reduz a afluência de água doce e esse reservatório.

\section{Reservatórios de São Domingos, Nenezinho e Flori}

Para os reservatórios de São Domingos, Nenenzinho e Flori, verificou-se que o cloreto predominou nas águas armazenadas, sendo que o açude mais próximo à nascente apresenta baixo teor de salinidade com classificação de águas bicarbonatadas, o que ao longo da bacia modifica-se para águas cloretadas mistas ou sódicas.

Para análise dos resultados encontrados, está apresentada na Tabela 4 a variação temporal da condutividade elétrica $(\mu \mathrm{S}$. $\left.\mathrm{cm}^{-1}\right)$ nos três reservatórios.

As águas do reservatório Nenenzinho apresentaram valores de condutividade elétrica elevados $\left(>677 \mu \mathrm{S} . \mathrm{cm}^{-1}\right)$, sendo em setembro de $2006\left(22.900 \mu \mathrm{S} . \mathrm{cm}^{-1}\right)$ a ocorrência do valor mais elevado. Vale ressaltar que esta campanha foi realizada no período seco, estando o nível de água do açude baixo, indicando um período de alta concentração de sais devido principalmente à evaporação. $\mathrm{O}$ processo de salinização do açude Nenenzinho também pode ser evidenciado pelas "manchas brancas" visíveis em suas margens no período seco, referentes às eflorescências salinas. Outra questão a abordar é a redução da contribuição da área com solo mais adequado para a produção de água doce afluente devido a presença do reservatório de Flori.

Nesse açude observa-se uma correlação significativa entre a salinidade e a ocorrência de chuva. Em fevereiro a precipitação ocorrida gerou uma renovação nas águas desse açude que passou para classificação doce em março retornando à condição salobra em abril. Isso aconteceu devido a diluição

Tabela 4 - Variação temporal da condutividade elétrica ( $\mu \mathrm{S}$. $\mathrm{cm}^{-1}$ ) nos reservatórios São Domingos, Nenenzinho e Flori

\begin{tabular}{l|l|l|l}
\hline Data & São Domingos & Nenenzinho & Flori \\
\hline $5 / 7 / 2006$ & 2880 & 12430 & 129 \\
\hline $7 / 10 / 2006$ & 3300 & 22900 & 136 \\
\hline $7 / 11 / 2006$ & 3570 & 12910 & 190 \\
\hline $5 / 12 / 2006$ & 3180 & 4230 & 128 \\
\hline $11 / 1 / 2007$ & 3480 & 6350 & 178 \\
\hline $1 / 2 / 2007$ & 4010 & 9200 & 217 \\
\hline $9 / 3 / 2007$ & 1784 & 677 & 190 \\
\hline $3 / 4 / 2007$ & 1995 & 953 & 143 \\
\hline $8 / 5 / 2007$ & 2080 & 1346 & 143 \\
\hline $3 / 6 / 2007$ & 1667 & 1594 & 180 \\
\hline $6 / 7 / 2007$ & 2270 & 1943 & 176 \\
\hline $1 / 8 / 2007$ & 2140 & 2020 & 193 \\
\hline $5 / 10 / 2007$ & 2630 & 2860 & 246 \\
\hline $9 / 11 / 2007$ & 2760 & 3410 & 257 \\
\hline
\end{tabular}


dos sais presentes nos sedimentos de fundo do reservatório (resíduos da evaporação) e devido ao aporte de sais presente no solo. Essa análise está de acordo com a dinâmica descrita em Fontes (2009) que avaliou a contribuição do solo por meio de sondagens elétricas verticais.

O açude de São Domingos por ser maior, apresenta pequena variação relativa em função dos fenômenos de precipitação e evaporação, ou seja, seu volume acumulado não possibilita uma modificação tão significativa nas concentrações relativas. Em março, a condutividade elétrica desse açude reduziu de 4.010 para $1.784 \mu \mathrm{S} . \mathrm{cm}^{-1}$ voltando a crescer em abril por conta da evaporação e aporte de sais provenientes da sua área de drenagem. Esse reservatório não teve suas águas renovadas, permanecendo com características salinas, esse fato é influenciado pela presença de dois barramentos a montante que diminui a vazão afluente.

Nota-se que a água do açude Flori apresenta concentrações iônicas compatíveis à água doce, não havendo variações significativas no período.

Após a ocorrência da chuva de fevereiro, até o final do monitoramento, a condutividade no reservatório de Nenenzinho aumentou 404\%, enquanto para os reservatórios de Flori e São Domingos, o aumento foi de $55 \%$ e $35 \%$, respectivamente. Comparando estes dados com o comportamento dos isótopos estáveis da água verifica-se que o reservatório que teve seu volume mais afetado pela evaporação (Flori) foi o que apresentou menor aumento na concentração dos sais no período analisado, indicando que a influência do tipo e uso do solo é mais significativa que a ação da evaporação.

\section{Comparação entre as características geométrica do lago e as condições de salinidade da água reservada}

Alguns parâmetros geométricos influenciam no risco de salinização dos reservatórios superficiais. Estes são definidos por meio da profundidade do açude, o volume máximo armazenável e a área de espelho d’água máxima; área da bacia hidrográfica (Molle e Cadier, 1992).

Os coeficientes de forma das curvas das encostas do açude $(\alpha)$ e de abertura do açude $(K)$ foram calculados para os reservatórios em estudo, exceto para o São Domingos por indisponibilidade de dados, utilizando a Equação 1, aplicando-se os valores constantes nas curvas cota $\mathrm{x}$ área $\mathrm{x}$ volume de cada reservatório. Os valores encontrados estão na Tabela 5, assim como a classificação da geometria do lago de acordo com a metodologia proposta por Molle e Cadier (1992).

A classificação do reservatório de França indica uma geometria propícia para evaporação, uma vez que apresenta valor do coeficiente de abertura elevado, indicando que este açude encontra-se em vales abertos e planos. As encostas côncavas favorecem a formação de açude com espelho d'água que não varia muito quando o nível de água baixa. Apesar da vulnerabilidade do lago a evaporação, não foi identificado processo de salinização nesse reservatório. De acordo com os valores isotópicos, suas águas são menos afetadas pela evaporação do que o reservatório de São José do Jacuípe, isso ocorre devido a sua localização em clima menos árido.

Os reservatórios de Nenenzinho e de São José de Jacuípe, de acordo com a classificação de Molle e Cadier (1992),
Tabela 5 - Classificação da geometria do lago dos reservatórios analisados

\begin{tabular}{|c|c|c|}
\hline Barragem & $\mathbf{V}=\mathbf{K}^{*} \mathbf{H}$ & $\begin{array}{l}\text { Classificação do } \\
\text { vale }\end{array}$ \\
\hline França & $\begin{array}{l}\mathrm{V} \\
80468 * \mathrm{H}^{2.2948} \\
\mathrm{R} 2=0.9867\end{array}$ & $\begin{array}{l}\text { encosta côncava e } \\
\text { vales abertos e } \\
\text { planos, relevo } \\
\text { pouco marcado }\end{array}$ \\
\hline $\begin{array}{l}\text { São José do } \\
\text { Jacuípe }\end{array}$ & $\begin{array}{l}\mathrm{V} \\
12065 * \mathrm{H}^{2.9636} \\
\mathrm{R} 2=0.9964\end{array}$ & 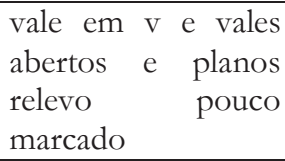 \\
\hline Nenenzinho & $\begin{array}{l}\mathrm{V} \\
4152.6^{* \mathrm{H} 2.9483} \\
\mathrm{R} 2=0.9998\end{array}$ & 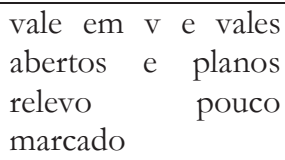 \\
\hline Flori & $\begin{array}{l}\mathrm{V} \\
1315.9 * \mathrm{H}^{3.1954} \\
\mathrm{R} 2=0.9712\end{array}$ & $\begin{array}{l}\text { vale em } \mathrm{v} \text { e vales } \\
\text { regulares relevo } \\
\text { ondulado médio }\end{array}$ \\
\hline
\end{tabular}

apresentam características geométricas que atribui vulnerabilidade a evaporação tanto pela presença de encostas em $\mathrm{V}$ como por apresentar vales abertos. O processo de salinização encontrado nesses reservatórios pode ser intensificado pela condição que a geometria do lago, que favorece a ação da evaporação.

Já o reservatório de Flori, apesar de apresentar encosta em V, tem geometria característica de relevo ondulado médio, o que resulta em menor vulnerabilidade a evaporação. Entretanto, deve-se observar o resultado de maior perda percentual do volume por efeito desse fenômeno, estimadas com base na variação isotópica no período de análise mais seco, encontrado em Fontes (2008). Essa análise indica que pequenos reservatórios independentes da sua geometria são vulneráveis as perdas por evaporação.

\section{CONCLUSÃO}

De acordo com os resultados encontrados para cinco reservatórios localizados na região semiárida, foram estabelecidas relações entre fatores climáticos (ocorrência de precipitação e ação da evaporação), características químicas da água armazenada e o comportamento hídrico dos reservatórios. As relações identificadas contribuem para o entendimento do processo de salinização dos reservatórios nessa região. Nas análises foram consideradas também informações da área de drenagem no que se refere ao aporte de sais proveniente da lavagem deste pela chuva, características geométricas do reservatório e suas dimensões.

A aplicação da análise isotópica para a avaliação dos fatores intervenientes do processo de salinização nos reservatórios estudados possibilitou a compreensão da dinâmica do comportamento hidrológico que determina a diluição ou concentração dos sais, se mostrando eficiente para caracterizar a ação da evaporação no processo de salinização e tempo de renovação e mistura das águas.

O acompanhamento da variação da composição isotópica no reservatório de França e São José possibilitou a comparação entre dois grandes reservatórios com dimensões e 
Fontes et al.: Avaliação dos fatores intervenientes no processo de salinização em reservatórios superficiais do semiárido brasileiro

comportamento distintos. O reservatório de França apresentou água menos afetada pela evaporação com a renovação da água armazenada para o período analisado. Esse comportamento isotópico reflete a eficiência na dinâmica hidrológica do reservatório do França no armazenamento de águas para a região nos aspectos de qualidade e quantidade, mesmo com a ocorrência de aporte de sais pela vazão afluente e a sua geometria favorecer as perdas por evaporação. Já para o reservatório de São José, a composição isotópica média bem mais rica em isótopos pesados, reflete o seu superdimensionamento que dificulta a renovação de suas águas. As águas armazenadas apresentam valores isotópicos característicos de intensa evaporação, prejudicando de forma significativa sua qualidade. O monitoramento da descarga de fundo confirma essa ineficiência, levando a concluir que águas afluentes ao reservatório levam cerca de seis meses para misturar e atingir o fundo do reservatório. Esse elevado tempo de residência intensifica o processo de degradação deste corpo d'água. Este comportamento hidrológico do São José, aliado a sua localização em ponto crítico de escoamento de águas salobras e salinas e sua geometria em vale aberto e em V, confere a esse reservatório problemas de salinização de suas águas. Outra questão é a presença do reservatório de França a montante que reduz a afluência de água doce para o de São José do Jacuípe. Comparando os resultados dos dois reservatórios verificou-se que a contribuição da área de drenagem foi o fator mais significativo para o processo de salinização.

A análise dos três reservatórios menores possibilitou a avaliação em um mesmo ambiente climático, mas com características de salinização distintas. O reservatório de Flori, situado próximo à nascente apresentou água doce durante todo o período analisado, o reservatório de Nenenzinho, situado no trecho médio a menos de $3 \mathrm{~km}$ de distância, apresentou água salgada no período seco e doce a salobra no período de chuvas intensas e o reservatório de São Domingos, situado a jusante, apresentou água salgada em todo o período. Cabe ressaltar que durante o monitoramento este reservatório, a contribuição da área de drenagem não foi suficiente para renovação de suas águas, o que é fortemente influenciada pela existência de barramentos a montante.

A caracterização isotópica das águas armazenadas demonstrou a influência do tamanho do reservatório na qualidade da água devido a diferentes características do balanço hídrico e possibilidade de renovação das águas. A análise dos pequenos reservatórios demonstra que reservatórios menores são mais susceptíveis a ação da evaporação, ao mesmo tempo em que possui águas de melhor qualidade devido à frequência de renovação destas. Entretanto reservatórios próximos (Flori e Nenenzinho) apresentaram comportamento distinto ressaltando a interferência da área de drenagem, tipo e uso do solo. A geometria do lago não apresentou influência significativa no presente estudo.

Diante desses resultados, conclui-se que salinização de reservatórios do semiárido tem dinâmicas diferenciadas por período, mas com destaque para a contribuição da área de drenagem. No período seco, a elevada taxa de evaporação típicas da região contribui no processo de concentrações de sais desses mananciais, no período de chuvas intensas, o aporte de sais é intensificado por afluentes salgados ou por sais presente no solo carreado pelas chuvas para os corpos d'água.

\section{REFERÊNCIAS}

BRAND, W. A.; AVAK, H.; SEEDORF, R.; HOFMANN, D.; CONRADI, T. New methods for fully automated isotope ratio determination from hydrogen at the natural abundance level, Geoph. Prosp, v. 28, p.967-976, 2000.

CAMERON E.M., HALL G.E.M., VEIZER J.; KROUSE H.R. Isotopic and elemental hydrogeochemistry of a major river system; Fraser River, British Columbia, Canada, Chemical Geology, v. 122, p.149-169, 1995.

CRAIG, H. Isotope standards for carbon and oxygen and conection factors for massspectrometric analysis of carbon dioxide, Geochimica et Cosmochimica Acta, v. 12, p. 133-149, 1957.

CRAIG, H. Isotope variations in meteoric waters, Science, v. 133, p. 1702-1703, 1961.

CLARK, I. FRITZ, P. Environmental Isotopes in Hydrology. New York: Lewis Press, 1997. vol. II

DANSGAARD, W. Stable isotopic in Precipitation. Tellus, v. 16, p.436-468, 1964.

DINCER T. The use of oxygen-18 and deuterium concentrations in the water balance of lakes. Water Resources Research, v. 4. p. 1289-1305, 1968.

EPSTEIN, S.; MAYEDA, T. Variations of 180 content of waters from natural sources, Geochimica et Cosmochimica Acta, v. 4, p. 213-221, 1953.

FONTES, A. S.; MEDEIROS, Y .D. P.; AZEVEDO, A. E. G.; ZUCCHI, M. R. Estimativas das perdas de evaporação em pequenos reservatórios por meio de isótopos estáveis - bacia experimental. In: SIMPÓSIO DE RECURSOS HÍDRICOS DO NORDESTE, 9, 2008, Salvador. Articulação de políticas públicas e Vulnerabilidade dos recursos hídricos, 2008.

FONTES, A. S.; AZEVEDO, A. E. G.; ZUCCHI, M. R.; MEDEIROS, Y.D.P. Investigação da contribuição do solo na salinidade dos reservatórios da Bacia Experimental da UFBA a partir da utilização de métodos geoelétricos. 2009. In: SIMPÓSIO BRASILEIRO DE RECURSOS HÍDRICOS, 18, Campo Grande, 2009.

FONTES, A. S.; ZUCCHI, M. R.; MEDEIROS, Y.D.P.; AZEVEDO, A. E. G. Estudo da dinâmica do fluxo de água na bacia do rio Jacuípe por meio de traçadores ambientais. Revista Brasileira de Recursos Hídricos, v. 16, p. 27-36, 2011.

MACHAVARAN M.; KRISHNAMURTHY R. Earth surface 
evaporative processes: a case study from the great lakes region of the United States based on deuterium excess in precipitation. Geochimica et Cosmochimica Acta, v. 59, p. 4279-4283, 1994.

GAT J. Environmental isotope balance of Lake Tiberias, Isotopes. Hydrology. IAEA: Vienna, Austria, p. 151-162, 1970.

GAT J. Oxygen and Hydrogen Isotopes in the Hydrologic Cycle.. Annual Review of Earth and Planetary Sciences, v. 24, p. 225-262, 1996.

GIBSON, J.; EDWARDS, T.; PROWSE, T. Development and validation of an isotopic method for estimating lake evaporation, Hydrological Processes, v. 10, p. 1369-1382, 1996.

GIBSON J. J. Short-term evaporation and water budget comparisons in shallow arctic lakes using non-steady isotope mass balance. Journal of Hydrology, v. 264, p. 242-261, 2002a.

GIBSON, J. J.; AGGARWAL, P.; HOGAN, J.; KENDALL, C.; MARTINELLI, L.; STICHLER, W.; RANK, D.; GONI, I.; CHOUDHRY, M.; GAT, J.; BHATTACHARYA, S.; SUGIMOTO, A.; FEKETE, B.; PIETRONIRO, A.; MAURER, T.; PANARELLO, H.; STONE, D.; SEYLER, P.; MAURICEBOURGOIN, L.; HERCZEG, A. Isotope studies in large river basins: a new global research focus, EOS, v. 83, p.613-617, 2002b.

HITCHON B.; KROUSE H. Hydrogeochemistry of surface waters of the MackenzieRiver drainage basin, Canada-iii. Stable isotopes of oxygen, carbon and sulphur. Geochimica et Cosmochimica Acta, v. 36, p. 1337-1357, 1972.

IAEA, International atomic energy agency and United Nations educational, scientific and cultural organization Environmental isotopes in the hydrological cycle.Principles and Applications. v. 1, 2002. Water Resources Programme. Disponível em: http:// www-naweb.iaea.org/napc/ih/documents/global_cycle/ Environmental $\% 20$ Isotopes $\% 20$ in $\% 20$ the $\% 20$ Hydrological $\% 20$ Cycle\%20Vol\%201.pdf. Acesso em maio 2014.

KENDALL, C.; COPLEN, T. Distribution of oxygen-18 and deuterium in river waters across the united states, Journal Hydrol. Processes, v. 15, p. 1363-1393, 2001.

LADOUCHE, B.; PROBST, A.; VIVILLED, D.; IDIRB, S.; BAQUEA, D.; LOUBETC, M.; PROBST, J.; BARIACA, T. Hydrograph separation using isotopic, chemical and hydrological approaches (strengbach catchment, france), J. Hydrology, v. 242, p. $255-274,2001$.

MOLLE, F. Marcos históricos e reflexões sobre a açudagem e seu aproveitamento. Série Hidrologia, Relatório Técnico n. 30, SUDENE, Recife, 1994.

MOLLE, F.; CADIER, E. Manual do pequeno acude. Recife: SUDENE, Convênios: SUDENE/ORSTOM; SUDENE/ TAPI, 1992. 521p
MOORE, R. Tracing runoff sources with deuterium and oxygen-18 during spring melt in a beadwater catchment, Southern Laurentians, Quebec. Journal of Hydrology, v. 112, p. 135-148, 1989.

PHILLIPS, F.; HOGAN, J.; MILLS, S.; HENDRICKX, J. Environmental tracers for assessing water and salt balances in arid-region river basins. Dubai, UAE, 2001.

ROZANSKI, K.; FROEHLICH, K.; MOOK, W. Environmental isotopes in the bydrological cycle. Principles and applications: Surface Water, UNESCO/IAEA, Paris, 2001. Volume 3.

SIMPSON, H.; HERCZEG, A. Stable isotopes as an indicator of evaporation in the river Murray, Australia, Water Resources Research, v. 27, p. 1925-1935, 1991.

TEIXEIRA, W.; TOLEDO, M.; FAIRCHILD, T.; TAIOLI, F. Decifrando a Terra. São Paulo: Companhia Editora Nacional, 2008.

VITVAR, T.; AGGARWAL, P. Global Network islaunched to monitor isotopes in rivers, Eos Trans. AGU, v. 88, p. 1-2, 2007.

VOROSMARTY, C.; MEYBECK, M. Responses of continental aquatic systems at the global scale: New paradigms, new methods, in Vegetation, Water, Humans and Climates, Germany: Springer, Heidelberg, 2004. 